\section{Main research areas}

There has been insufficient epidemiological research. This explains the lack of reliable information that would be expected of current evidence-based mental health approaches. Funding for medical research through the National Council for Scientific and Technical Investigations is almost nonexistent. Under these conditions, research in the biomedical areas is restricted to the pharmaceutical industry.

In contrast, within Buenos Aires a psychoanalytical tradition, dating back to the 1940s, has developed. It is at present considered the 'most psychoanalysed city' in the world. Two psychoanalytical societies are affiliated with the International Psychoanalytical Association. Psychoanalysis has exerted a powerful influence on the mental health system, and still constitutes a very important part of the psychiatric curriculum.

\section{Human rights}

There are several laws that regulate compulsory admission to hospital, the status of people under guardianship (including property) and periodical review of those patients compulsorily admitted. Again, these regulations vary across the provinces.

Progress has been made in relation to the traumatic sequelae of the so-called 'dirty war' (1976-83). Mental health professionals have been organised to assist with the restitution of children abducted by the military. Several nongovernmental organisations are widely involved with the subject of human rights and the prominent socioeconomic inequalities in health. There is still much work to be done in this area, particularly in relation to housing. With the presence of a stable democratic government, it is very much hoped that the necessary changes will soon be implemented.

\section{Sources}

Adaszko, D. \& Salvia, A. (2010) Poverty and Deprivation Conditions in the Great Urban Centers. Catholic University of Argentina.

Alperin, M. N. P. (2009) The impact of Argentina's social assistance program plan jefes y jefas de hogar on structural poverty. Estudios Economicos, 20 (número extraordinario), 49-81.

Ceriani, L., Obiols, M., Michaelewicz, A., et al (2009) Obstáculos para el desarrollo de políticas transformadoras en salud mental: el caso de la ley 25.421. [Obstacles against the development of policies and the implementation of improvements in mental health: the case of law 25.421.] Investigaciones en Psicología, 14, 7-19.

Cia, A., Cordoba, R. N. \& Abib Adad, M. (2010) Current clinical advances and future perspectives of the psychiatry/mental health field in Latin America. International Review of Psychiatry, 22, 340-346.

Garay, C. J. \& Korman, G. P. (2008) Clinical guidelines in mental health: situation in Argentina. Vertex, 19, 491-495.

Hollander, N. C. (1989) Psychoanalysis confronts the politics of repression: the case of Argentina. Social Science and Medicine, 28, 751-758.

Lupu, N. \&. Stokes, S. (2010) Democracy, interrupted: regime change and partisanship in twentieth-century Argentina. Electoral Studies, 29 91-104.

Ohman, L. (2009) The reform in the Central Psychiatric Unit. Vertex, 20, 51-61.

Pellegrini, J. (2004) Social crisis, human rights and public hospital. Vertex, 15, 147-155.

Penchaszadeh, V. B. (1992) Abduction of children of political dissidents in Argentina and the role of human genetics in their restitution. Journal of Public Health Policy, 13, 291-305.

Saxena, S., Sharan, P., Garrido, M., et al (2006) World Health Organization's Mental Health Atlas 2005: implications for policy development. World Psychiatry, 5, 179-184.

Toro Martinez, E. (2008) Substance use disorder. Forensic issues in Argentina. Vertex, 19, 537-542.

Torricelli, F. \& Barcala, A. (2004) Epidemiology and mental health: an impossible analysis in Buenos Aires city. Vertex, 15, 10-19.

World Health Organization (2005) Mental Health Atlas 2005. WHO.

World Health Organization (2011) Mental Health System in 10 Argentine Provinces: Jujuy, Salta, Tucuman, Corrientes, Catamarca, Mendoza, San Juan, Chubut, Rio Negro, and Tierra del Fuego. Results of an Assessment by the WHO-AIMS. WHO (in press).

Yanco, D. \& Roma, V. (2007) Mental health internships in Buenos Aires. Vertex, 18, 179-186.

\title{
Mental health in Botswana
}

\section{Paul Sidandi ${ }^{1}$ MRCPsych, Philip Opondo ${ }^{2}$ MMed Psych and Sebonetse Tidimane ${ }^{3}$ RN FNP}

'Senior Consultant Psychiatrist, ${ }^{2}$ Consultant Psychiatrist, ${ }^{3}$ Nursing Superintendent, Jubilee Psychiatric Unit, Nyangabgwe Hospital, Francistown, Botswana, email paul.sidandi@yahoo.com

B otswana is a landlocked country located in southern Africa. More than two-thirds of it (70\%) is covered by the Kalahari Desert, known locally as the Kgalagadi. The majority ( $82 \%)$ of the nearly 2 million population live in the eastern part, along the railway line from Lobatse in the south-east to Francistown in the north-east, and the rest in the central part, including the Okavango River delta.

Botswana is about the size of Kenya, France or the State of Texas and is thinly populated. The surface area is $581730 \mathrm{~km}^{2}$ (363581 square miles). This poses a challenge in the provision of health services in general and psychiatric services in particular. About $45 \%$ of the population is under
15 years of age. Over $50 \%$ are settled in urban areas. The four main centres are: the capital city, Gaborone (population 250000), in the south-east; the second city, Francistown (105000), in the north; Lobatse (60000); and Selebi-Phikwe (50000).

It is a multiparty democracy that became independent from Britain in 1966. It has achieved the status of a middle-income country with P12.18 billion (US\$1.2 billion) in its annual development budget and P27.14 billion (US\$4.17 billion) in its recurrent budget. Its national income per capita (PPP international \$) in 2009 was \$13310. Total expenditure on health per capita was $\$ 1341$ and total expenditure on health as a 
proportion of gross domestic product was 10.3\%. Around $80 \%$ of the health budget is provided by the government.

The ongoing global economic difficulties have led to the postponement of most development projects. The economy is closely linked with South Africa. As one of the poorest countries before independence, Botswana depended on migrant mine labour remittances from that country. The health of ex-miners was a public health issue at the time and some still receive compensation for lung diseases. Unemployment is high at $18 \%$ and this remains a social problem.

\section{Health services}

The government health services are divided into a two-tier system, one tier based in health facilities and the other in the community. The facility-based services are organised in a pyramidal structure, with referral hospitals at the apex. There are three national referral hospitals, one of which is a psychiatric hospital. At the bottom of the pyramid are mobile stops, health posts and clinics which are manned by nursing staff and grouped into clusters with a doctor. Communitybased clinics, which were previously under the Ministry of Local Government, are now run by district health management teams under the Ministry of Health.

The country has 3816 hospital beds. In January 2010, a second 200-bed private hospital was opened in Gaborone. The teaching hospital will add 400 beds when it opens in 2014. There are 390 psychiatric beds, constituting 10\% of the total. HIV accounts for $18 \%$ of the admissions at Sbrana Psychiatric Hospital. The 2009 Botswana AIDS Impact Survey III reported a national HIV prevalence rate of $17.6 \%$.

\section{Role of religious practices}

Botswana is mainly a Christian country, with the majority belonging to the main denominations. However, there are a growing number of spiritual, apostolic and revival charismatic churches and many still follow indigenous religious practices. There are a number of converts to Islam. Some patients visit churches for prayer, holy water and laying on of hands.

\section{Policy on traditional medicine}

The traditional healers are represented by the Botswana Dingaka Association. The Ministry of Health has adopted a policy of recognising them and promoting good working relations between them and modern scientific practice. Many patients combine the use of traditional medicine with hospital-based treatment and spiritual healers. Traditional healers are consulted mostly for the management of problems arising from psychological and cultural factors.

\section{Mental health services}

The 300-bed Sbrana Psychiatric Hospital in Lobatse has four psychiatrists. It opened in 2009 to replace the 180-bed Lobatse Mental Hospital, which had been in existence from 1938. Sbrana Psychiatric Hospital is a stand-alone fully serviced hospital with teaching and forensic facilities and separate child, adolescent and psychogeriatric wards, a mother and baby unit and an observation ward, as well as acute, chronic and rehabilitation wards. It has a day hospital, psychology, social work, occupational therapy and pharmacy services.

The Jubilee Psychiatric Unit, Nyangabgwe Hospital, has two psychiatrists. It opened in 1980, initially with four beds. The capacity had increased to 34 beds (22 male and 12 female) when the in-patient wing was closed in October 2010 to pave way for the establishment of an infectious diseases unit. The majority of in-patients were transferred to Sbrana Psychiatric Hospital in Lobatse. A few were transferred to Sekgoma Memorial Hospital Psychiatric Unit in Serowe Village (population just under 53000), about $200 \mathrm{~km}$ away.

The Jubilee Psychiatric Unit now has only eight holding beds (five for males and three for females). Patients who need in-patient care for more than a day or two are transferred to the Sbrana Psychiatric Hospital, a distance of approximately $500 \mathrm{~km}$. The Psychiatric Unit at Sekgoma Memorial Hospital will be improved in the interim to function as the referral centre for psychiatry in the northern part of the country, pending the construction of a 100-bed facility in Francistown when the economy improves.

The newly built Mahalapye, Sekgoma, Scottish Livingstone and Letsholathebe II Memorial Hospitals have psychiatric units with 20-30 beds each. Other hospitals, including Princess Marina Hospital, a national referral facility in Gaborone, offer out-patient psychiatric clinic services but have no in-patient beds.

Mental health services are provided by eight psychiatrists, as well as medical officers, psychologists, occupational therapists, social workers, psychiatric and general nurses. There are also about 100 community health nurses. Psychiatric nurses, who have to have the Diploma in Advanced Community Mental Health Nursing (see 'Training'), form the backbone of psychiatric care outside the referral hospitals. They carry out extensive outreach in their respective catchment areas. This complements the airborne and road-trip outreach clinics by the psychiatrists based in Francistown and Lobatse. The district and primary hospitals, including mine, mission and military hospitals, have one or more psychiatric nurses, who admit patients to the general wards and transfer only the unmanageable ones to Lobatse or Francistown.

In comparison with other African countries, Botswana appears to be better staffed but the geographical spread means the workforce is overstretched. For example, Botswana has the same area as Kenya, which has a population 20 times greater, with 67 psychiatrists.

\section{Psychiatric association}

As there are only eight psychiatrists, including two in private practice (one general and one child psychiatrist) in Gaborone, there is no Botswana Psychiatric Association affiliated to the World Psychiatric Association. The Botswana Association for Psychosocial Rehabilitation (BAPR), which runs a day-care centre in Lobatse, is the only non-governmental organisation functioning in the community in this field. It is affiliated to the World Association for Psychosocial Rehabilitation and groups together professionals, families, consumers and policy makers. 
Unpublished reports indicate that stigma contributes to only a few health workers opting to take psychiatry and psychiatric nursing as a discipline for specialisation.

\section{Training}

The Institute of Health Services, Lobatse campus, runs an 18-month Diploma in Advanced Community Mental Health Nursing course. The University of Botswana opened its School of Medicine in August 2009 with the intake of the first MBBS undergraduates. It is on schedule to establish a 400-bed academic hospital in Gaborone. Psychiatry will be offered as a modular course for the undergraduates and will be allocated one month of study on the postgraduate course in family medicine (see http://www.ub.bw).

\section{Mental health disorders}

According to the annual reports of the Lobatse Mental Hospital and Jubilee Psychiatric Unit for the years 2005-08, the five conditions most commonly presenting in the inpatient unit were:

1 schizophrenia

2 depressive disorders

3 alcohol use disorders

4 bipolar affective disorders

5 epilepsy.

In the out-patient unit they were:

1 schizophrenia

2 cannabis-induced disorders

3 depressive disorders

4 alcohol use disorders

5 epilepsy.

\section{Mental health legislation}

The current law was enacted in 1971 (5 years after independence) and is due to be reviewed and updated.

\section{Mental health policy}

The July 2003 Botswana National Policy on Mental Health provides a framework for the incorporation of the objectives of the mental health programme into the existing general health services. The aim of the policy is to provide access to services, to enable every individual to have the benefit of good mental health and thus allow them to make an optimal contribution to personal, community and national development.

\section{The future of mental health services}

As in the USA (Bernstein et al, 2010), although society's perception of individuals with mental illness has improved, stigma is still significant in Botswana. With the opening of Sbrana Psychiatric Hospital, there is hope that the facility will be accredited along with other major general hospitals by the Council for Health Service Accreditation of Southern Africa (COHSASA) as meeting international standards.

\section{Sources}

Bernstein, C. A., Hershfield, B. \& Cohen, D. C. (2010) Psychiatry in the USA: an overview. International Psychiatry, 7, 90-92.

World Health Organization (2009) World Health Statistics. WHO. At http://www.who.int/countries/bw/en (accessed January 2011).

\section{Criteria for compulsory admission in some European countries}

\section{A. Carballedo ${ }^{1}$ and M. Doyle ${ }^{2}$}

1Senior Registrar in Psychiatry, Cheeverstown House, Dublin, Ireland, email carbala@tcd.ie; ${ }^{2}$ Registrar in Psychiatry, St James Hospital, Dublin, Ireland

\begin{abstract}
Compulsory admission to mental health facilities is a controversial topic, as it impinges on personal liberty and the right to choose, and it carries the risk of abuse for political, social and other reasons (Gostin, 2000). However, involuntary admission can prevent harm to self and others, and assist people in attaining their right to health, which, due to their mental disorder, they are unable to manage voluntarily. Since the 1950s and 1960s, the delivery of mental health has shifted from a paternalistic emphasis on the need to treat those who are not able to look after themselves, to the rights of patients who have a mental illness. The Principles for the Protection of Persons with Mental
\end{abstract}

Illness ('the MI Principles') adopted by the United Nations in 1991 play an important role in raising awareness about the human rights of people with mental health problems. They provide guidance on areas such as the procedures for involuntary admission to mental health facilities and standards of care (Knapp et al, 2007). Legal frameworks for involuntary placement of those who are mentally ill have been reformed in many European countries. Most regulate compulsory admission and treatment by special mental health laws. Only Greece, Spain, Italy and those member states of the European Union (EU) that joined in 2004 and 2007 have no separate laws (Dressing \& Salize, 2004). 